\title{
Correction to: A Scoping Review of HIV Pre-exposure Prophylaxis Stigma and Implications for Stigma-Reduction Interventions for Men and Transwomen Who Have Sex with Men
}

\author{
A. Lina Rosengren ${ }^{1}\left({ }^{10} \cdot\right.$ Corina Lelutiu-Weinberger $^{2} \cdot$ E. Wilbur Woodhouse $^{3} \cdot$ Priyadharshiny Sandanapitchai $^{4}$. \\ Lisa B. Hightow-Weidman ${ }^{1}$
}

Published online: 23 January 2021

(c) Springer Science+Business Media, LLC, part of Springer Nature 2021

\section{Correction to: AIDS and Behavior}

https://doi.org/10.1007/s10461-020-03135-2

The original version of this article unfortunately contained a mistake in the name of the corresponding author. The correct name of the author "A. Lina Rosengren-Hovee" should be "A. Lina Rosengren".

The original article has been corrected.

Publisher's Note Springer Nature remains neutral with regard to jurisdictional claims in published maps and institutional affiliations.

The original article can be found online at https://doi.org/10.1007/ s10461-020-03135-2.

A. Lina Rosengren

lina_roho@med.unc.edu

1 Division of Infectious Diseases, Department of Medicine, University of North Carolina, 130 Mason Farm Road, Chapel Hill, NC 27599, USA

2 School of Nursing, Rutgers Biomedical and Health Sciences, François-Xavier Bagnoud Center, Rutgers University, 65 Bergen Street, Room 846N, Newark, NJ 07107, USA

3 Department of Medicine, Vanderbilt University Medical Center, 1161 21st Avenue South, Nashville, TN 37122, USA

4 François-Xavier Bagnoud Center, Rutgers University, 65 Bergen Street, Newark, NJ 07107, USA 